Thorax (1974), 29, 134.

\title{
Cardiac and pulmonary fat embolectomy for suspected fat embolus
}

\author{
CYRILS. NELSON \\ Queen Elizabeth Hospital, University of the West Indies, Barbados, West Indies
}

\begin{abstract}
Nelson, C. S. (1974). Thorax, 29, 134-137. Cardiac and pulmonary fat embolectomy for suspected fat embolus. There is no specific treatment of fat embolism, whether the embolism is predominantly cerebral, pulmonary, renal or mesenteric.

A 46-year-old man had fractured his right femur for the third time in December 1971. Seventy hours later he suddenly developed the cardiovascular, respiratory, and cerebral manifestations of post-traumatic fat embolism. His chest radiograph at the onset of symptoms was consistent with fat embolism. He underwent cardiac and pulmonary embolectomy on 7 December 1971 and made a most dramatic recovery. His haemobronchorrhoea, dyspnoea, tachypnoea, hyperpyrexia, and profound shock disappeared at the end of the operation. His only postoperative cerebral disturbance was mild disorientation.

The pathophysiological changes accompanying fat embolism are due to toxic vasculitis and fat macroglobule aggregations blockading the pulmonary arterioles and capillaries. The blockading concept is the basis for cardiac and pulmonary fat embolectomy. Only a larger series embodying a multicentre trial will show whether or not cardiopulmonary fat embolectomy is a specific treatment of massive fat embolism.

The purpose of this paper is to report on the technique and result of embolectomy for a suspected fat embolus following fracture of the femur.
\end{abstract}

\section{CASE HISTORY}

Neblett D. sustained a recurrence of his previously fractured and amputated right femur. He first fractured this femur in 1950 when he had an above-knee amputation and fractured the same stump again in 1970. All three fractures were impact injuries in motor vehicle accidents.

The third fracture was not manipulated and his course was completely uneventful until he suddenly became breathless 70 hours after injury. He had no chest pain but coughed up profuse, frothy, bloodstained sputum. Shortly after the onset of the pulmonary symptoms he went into peripheral circulatory failure and also became pyrexial $\left(100.2^{\circ} \mathrm{F} ; 39.9^{\circ} \mathrm{C}\right)$. He developed neurological disturbances which progressed from restlessness, agitation, disorientation, and delirium to semicoma. The absence of petechiae was probably due to the fact that these are difficult to detect in the black race and they also may develop very late. A diagnosis of fat embolism of the lungs was made. During the next 18 hours he became moribund in spite of heparin and nasal oxygen.

His admission haemoglobin was $12.0 \mathrm{~g} \%$ but this dropped to $8.5 \mathrm{~g} \%$ on 6 December 1971 .

Other notable laboratory changes were:

\begin{tabular}{|c|c|c|c|}
\hline & 6 Dec. 1971 & 7 Dec. 1971 & $\begin{array}{l}\text { Postop. } \\
\text { 8 Dec. 1971 }\end{array}$ \\
\hline $\mathrm{NA}+(\mathrm{mEq} / \mathrm{l})$ & 148 & 140 & 137 \\
\hline $\mathrm{K}+(\mathrm{mE}$ & $5 \cdot 1$ & $4 \cdot 8$ & $4 \cdot 4$ \\
\hline $\mathrm{Cl}++(\mathrm{mEq} / \mathrm{l})$ & 100 & 108 & 103 \\
\hline Bicarbonate & 18 & 22 & 11 \\
\hline Urea (mg\%) & 48 & 142 & 106 \\
\hline $\mathrm{WBC} / \mathrm{mm}^{3}$ & 13,800 & 31,500 & - \\
\hline
\end{tabular}

Daily chest radiographs were taken from the onset of respiratory symptoms. The preoperative and first postoperative films are shown (Figs 1 and 2).

OPERATION A full-length sternotomy incision was employed. The pericardium was opened medial to the phrenic nerve. A double purse-string Ethiflex $2 / 0$ was inserted about $1 \mathrm{~cm}$ distal to the pulmonary valve. A piece of non-collapsible Portex tubing was then attached to the sucker and this tubing was afterwards clamped. A Cooley's clamp was applied to the greatly distended pulmonary artery deep to the purse strings. The artery was then incised and the clamped tube sucking at $200 \mathrm{mmHg}$ was inserted into both branches of the pulmonary artery three times (Fig. 3). Next, both the pulmonary artery and the ascending aorta were cross-clamped with a Bahnson's clamp placed 


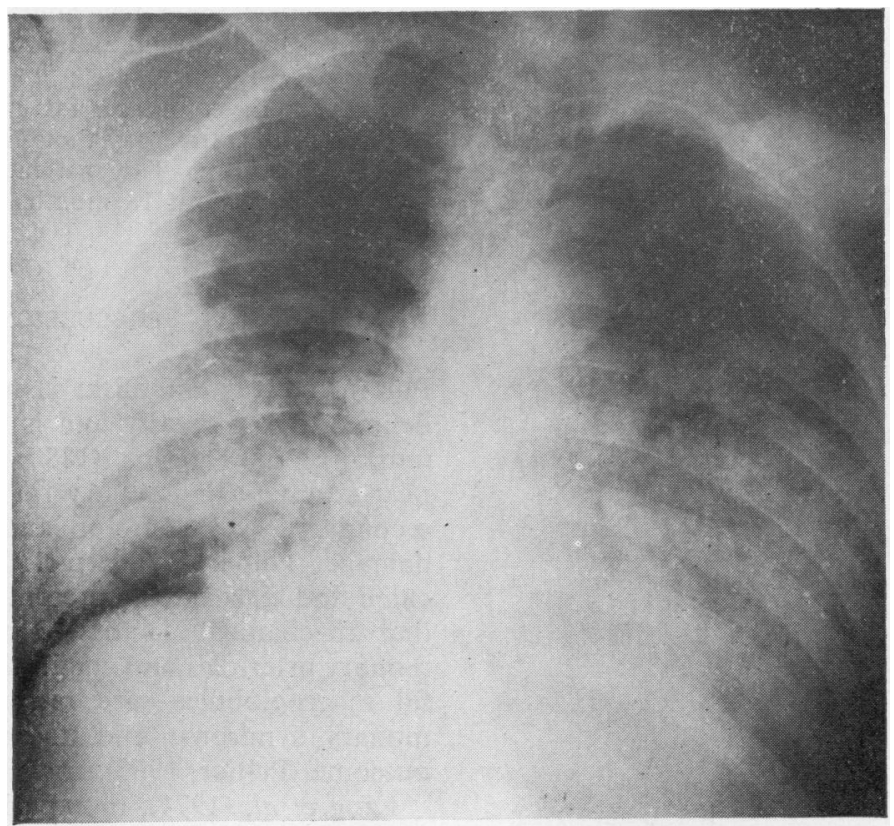

FiG. 1. Film taken a few hours after the onset of respiratory symptoms. The dense bilateral opacities indicating fat embolism are striking features.

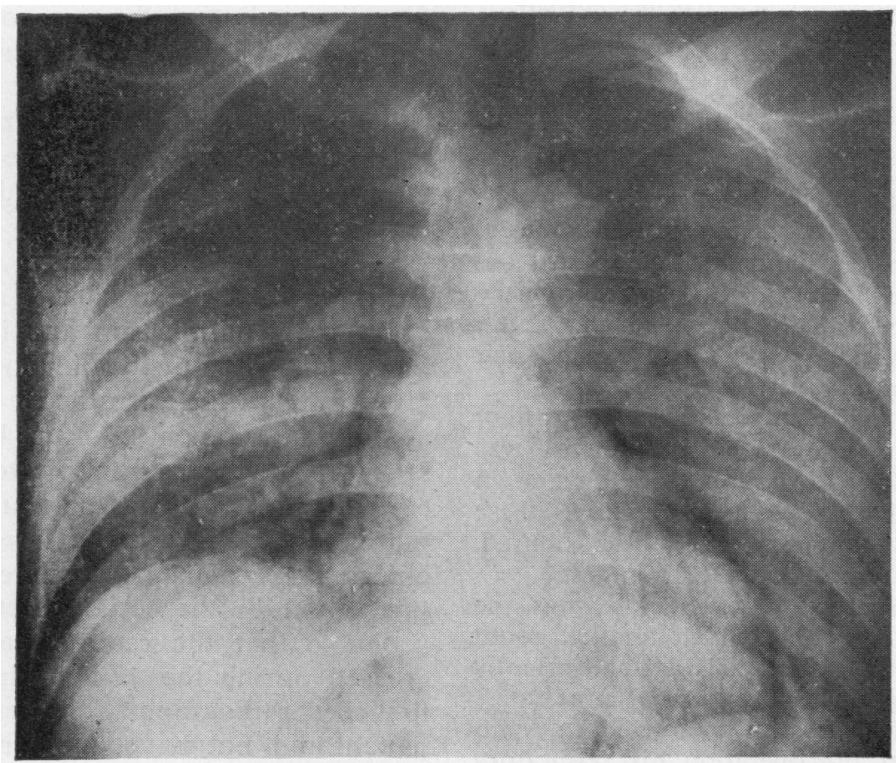

FIG. 2. Portable chest radiograph about 15 minutes after pulmonary fat embolectomy. Note marked improvement. 


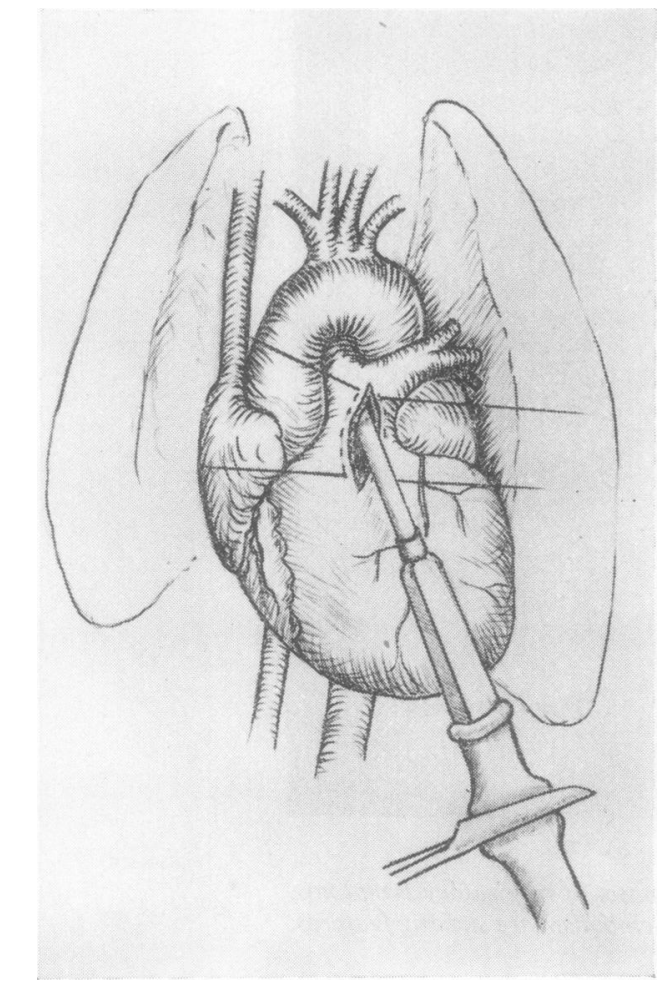

FIG. 3. Portex perfusion tubing applied to sucker and entering right pulmonary artery before haemostatic clamp was removed.

into the transverse sinus. At this stage the Cooley's clamp was released and the heart allowed to eject about six times. With the Bahnson's clamp still on, the sucker was again inserted into the pulmonary artery and the blood proximal to the Bahnson's clamp was sucked out. This clamp was then released and both branches of the artery were again sucked out.

Total clamping of the aorta or pulmonary artery lasted about one minute, but the anaesthetist was asked to hyperventilate the patient and maintain hypertension especially before cross-clamping these vessels. Finally, the pulmonary artery was sutured. Total operating time was 2 hours 10 minutes.

Thick molasses-like blood, but no clots, was the striking feature of the aspirate which totalled about 3 litres. Unfortunately, this blood was inadvertently discarded before being sent for full analysis for fat.

His postoperative recovery was completely uneventful and at the end of the operation his respiratory distress disappeared dramatically and he was fully aware of his environment. However, his disorientation waxed and waned for 48 to 72 hours. Nasal oxygen was continued for a few hours, but anticoagulation, digoxin, frusemide, and antibiotics were continued for 10 days.

His sputum contained fat macroglobules on the second postoperative day though this is not diagnostic of fat embolism. The patient is now completely asymptomatic about 18 months after operation.

\section{DISCUSSION}

Pulmonary fat embolism is now recognized as a definite clinical entity and is the cause of a high mortality rate. Scriba (1880) postulated that the post-traumatic pulmonary fat manifestations were secondary to vasomotor and respiratory centre damage. Peltier, between 1955 and 1968, advocated and clarified the present theory. He believed that mechanical factors-blockage of the pulmonary arterioles and capillaries by the aggregated fat macroglobules-are responsible for the pulmonary syndrome and its associated high fatal outcome (Peltier, 1965).

King et al. (1971), in experimental studies, supported the mechanical theory but, in addition, suggested toxic pulmonary vasculitis. The combination of capillary and arteriolar obliteration and vasculitis leads to a haemobronchorrhoea. The perfusion defect, the haemodynamic dysfunction, and the haemobronchorrhoea causing upper airway obstruction are not only responsible for respiratory distress but are the cause of the high mortality.

Weisz and Steiner (1971) summarized the causes of death in 31 cases of post-traumatic fat embolism. In spite of good intensive, supportive, nonspecific therapy, there were 22 deaths. Only those with mild pulmonary and neurological symptoms survived.

We support the mechanical pulmonary vascular occlusion theory. Faced with a moribund patient, I felt that continuation and improvement of his nonspecific therapy would not save his life. The physician and the anaesthetist also considered that death was imminent and that his life could not be saved by any means. Embolectomy was undertaken to remove the fat macroglobules in the heart, the pulmonary artery, and its major branches. His clinical improvement correlates well with the improvement in the serial chest radiographs. It is probable that the radiological opacities had increased during the 12-hour interval between the first chest radiograph and the embolectomy, but the patient did not have another preoperative chest radiograph.

His dramatic improvement cannot be attributed to his brief anaesthesia. Ross (1970) showed that 
deterioration occurs after limited intermittent positive pressure ventilation.

As far as I am aware, this is the first case of cardiopulmonary embolectomy for suspected fat emboli. The operation produced a most dramatic improvement in the condition of the patient. It was thought that he could not survive in spite of any form of treatment.

Credit is due to my secretaries, Jean Whitehead and June Hood, to Willie Alleyne Associates, photographers, and to Carl Broodhagen, artist. I am greatly indebted to Dr. F. Reader, the anaesthetist, who was assisted by Dr. I. C. Kim.

\section{REFERENCES}

King, E. G., Wagner, W. W., Ashbaugh, D. G., Latham, L. P., and Halsey, D. R. (1971). Alterations in pulmonary microanatomy after fat embolism. Chest, 59, 524.

Peltier, Leonard F. (1965). The diagnosis of fat embolism. Surgery, Gynaecology and Obstetrics, 121, 371.

Ross, A. P. J. (1970). The fat embolism syndrome: with special reference to the importance of hypoxia in the syndrome. Annals of the Royal College of Surgeons of England, 46, 159.

Scriba, J. (1880). Untersuchungen über die Fettembolie. Deutsche Zeitschrift für Chirurgie, 12, 118.

Weisz, G. M. and Steiner, E. (1971). The cause of death in fat embolism. Chest, 59, 511. 